\title{
Effect of Indomethacin on Cerebral Blood Flow and Oxygenation in the Normal and Ventilated Fetal Lamb
}

\author{
FRANK VAN BEL, ${ }^{1}$ BEATRIJS BARTFLDS, DAVID F. TEITEL, AND ABRAHAM M. RUDOLPII \\ Cardiovascular Research Institute and Departments of Pediatrics, Physiology, and Obstetrics, \\ Gynecology and Reproductive Sciences. University of California at San Francisco. \\ San Francisco, California 94143
}

ABSTRACT

\begin{abstract}
Indomethacin lowers fetal and neonatal brain blood flow and may reduce the risk of periventricular-intraventricular hemorrhage. However, concerns have been raised that cerebral $\mathrm{O}_{2}$ metabolism may be compromised at lower cerebral perfusion pressures. In 17 near-term lamb fetuses, changes in brain blood flow and cerebral $\mathrm{O}_{2}$ metabolism $\left(\mathrm{CMRo}_{2}\right)$ were measured at mean carotid arterial pressures (MCBP) ranging from 8 to $70 \mathrm{~mm}$ $\mathrm{Hg}$. MCBP was adjusted by inflating balloon occluders around the aortic isthmus and brachiocephalic trunk. This was done before and during intrauterine pulmonary ventilation and oxygenation. Nine fetuses were pretreated with indomethacin (1 $\mathrm{mg} / \mathrm{kg}$ i.v.); eight served as controls. Changes in brain blood flow were assessed from carotid arterial blood flow $\left(\mathrm{Q}_{\text {car }}, \mathrm{mI} / \mathrm{min}\right)$ measured with flow transducers. In 15 animals, brain blood flow was also measured intermittently by radionuclide-labeled microspheres $\left(\mathrm{Q}_{\text {brain }}\right) . \mathrm{Q}_{\text {car }}$ correlated closcly with $\mathrm{Q}_{\text {briuin }}(r-0.94$, $p<0.0001)$; this relationship was not altered by indomethacin or by ventilation with oxygen. In the nonventilated fetuses, indomethacin decreased $Q_{c a r}$ at pressures above the lower limit of cerebral autoregulation $(43 \mathrm{~mm} \mathrm{Hg}$ ). However, at MCBP below $44 \mathrm{~mm} \mathrm{Hg}, Q_{\text {car }}$ with indomethacin was not significantly different from controls. $\mathrm{CMRO}_{2}$ fell when MCBP was decreased below $30 \mathrm{~mm} \mathrm{Hg}$ (range $8-29 \mathrm{~mm} \mathrm{Hg}$ ), but there was no significant
\end{abstract}

Indomethacin, a cyclooxygenase inhibitor, is increasingly being used to prevent preterm birth by inhibition of labor. In neonates, it is used extensively to close the patent ductus arteriosus. Recently, indomethacin has been shown to decrease the risk of severe neonatal PIVH when given early after birth $(1-5)$. Birth asphyxia with subsequent prostaglandin-induced postasphyxial hyperperfusion of the neonatal brain may facilitate the occurrence of PIVH $(6,7)$. It has been thought that indomethacin attenuates brain blood flow at higher cerebral

Recejved August 3. 1994; accepted February 23, 1995.

Correspondence: Frank van Bel, M.D., Department of Pediatrics, University Hospital Leiden, P.O. Box 9600, 2300 RC Leiden, The Netherlands.

Supported by United States Public Health Service Grant HL 35842

${ }^{1}$ Recipient of the Ter Meulenfund of the Netherlands Academy of Arts and Sciences. difference between control and indomethacin-pretreated fetuses. In the ventilated fetuses, indomethacin reduced the slope of the pressure-flow relationship above the lower limit of cerebral autoregulation $(43 \mathrm{~mm} \mathrm{Hg})$, suggesting improved cerebral autoregulation. When $\mathrm{MCBP}$ was decreased below $44 \mathrm{~mm} \mathrm{Hg}$ (range $10-43 \mathrm{~mm} \mathrm{Hg}$ ), indomethacin did not lower $\mathrm{Q}_{\mathrm{car}}$ or $\mathrm{CMRo}_{2}$ as compared with controls. We conclude that indomethacin reduced cerebral perfusion in the nonventilated fetuses and also appeared to improve cerebral autoregulatory function in the ventilated and oxygenated fetuses, without compromising cerebral metabolism at lower cerebral perfusion pressures. (Pediatr Res 38: 243-250, 1995)

\section{Abbreviations}

$\mathrm{CMRO}_{2}$, cerebral metabolic rate of oxygen

$\mathrm{Co}_{2}$, blood oxygen content

ID, inner diameter

MCBP, mean carotid blood pressure

OD, outer diameter

PIVII, periventricular-intraventricular hemorrhage

$\mathrm{Q}_{\text {car }}$, carotid arterial blood flow

$\mathrm{Q}_{\text {brain }}$, brain blood flow determined by radionuclide-labeled microspheres

perfusion pressures and modulates the vasodilatory effect of hypercapnia on cerebral resistance vessels $(8,9)$. Recent reports $(10,11)$ also suggest that cyclooxygenase inhibitors enhance the autoregulatory ability of the neonatal cerebral vascular bed, which also may contribute to the decrease in the occurrence of PIVH. However, it has been suggested that the indomethacin-induced decrease of ccrebral blood flow at cerebral perfusion pressures near and below the lower limit of cerebral autoregulation may compromise cerebral oxygen metabolism (12). This could facilitate the occurrence of brain white matter lesions such as a periventricular leukomalacia (13).

We investigated the influence of indomethacin on brain blood flow and metabolism over a wide range of cerebral 
perfusion pressures in the preterm lamb fetus. This was done before and again during pulmonary ventilation and oxygenation, because we were interested in the influence of indomethacin on the cerebral circulation before and shortly after birth. Pulmonary ventilation and oxygenation have been shown to induce alterations in brain blood flow comparable to those occurring at birth (14).

\section{METHODS}

Animals and surgical preparation. We studied 17 fetal sheep with gestational ages ranging from 123 to $135 \mathrm{~d}$ and weights ranging from 2550 to $4665 \mathrm{~g}$. All surgical and experimental procedures were approved by the Animal Care and Use Committee at the University of California, San Francisco. The ewe was fasted for at least $24 \mathrm{~h}$ before surgery. After local anesthesia with $2 \%$ lidocaine, low epidural anesthesia was achieved with $4 \mathrm{~mL}$ of $1 \%$ tetracaine hydrochloride (pontocaine HCL; Breon Laboratories, New York, NY). Polyvinyl catheters (1.3-mm ID, $2.3 \mathrm{~mm}$ OD) were advanced into the descending aorta and inferior vena cava of the ewe. $\mathrm{NaCl} 0.9 \%$ solution was infused continuously into the ewe, and 50-100 mg of ketamine hydrochloride (Vetalar; Parke-Davis, Morris Plains, NJ) were administered i.v. to the ewe every $10-15 \mathrm{~min}$ to maintain sedation.

Through a midline incision in the ewe's abdomen, the pregnant horn of the uterus was exposed, and a uterine incision was made overlying the fetal hind limbs. Local anesthesia was accomplished with $0.5 \%$ lidocaine hydrochloride before each fetal skin incision. Also $5 \mathrm{mg}$ of ketamine per $\mathrm{kg}$ of estimated fetal weight was given i.m. to the fetus. Polyvinyl catheters (0.75-mm ID, 1.2-mm OD) were passed to the fetal descending aorta and inferior vena cava via the hind limb vessels. The fetal skin and uterine incisions were sutured. A second incision was made over the left chest of the fetus. Through a thoracotomy in the third intercostal space, a catheter $(0.75-\mathrm{mm} \mathrm{ID,} 1.2-\mathrm{mm}$ OD) was placed into the brachiocephalic trunk from the internal thoracic artery. A specially constructed catheter was placed directly in the left atrium (20-gauge i.v. catheter, Becton Dickinson, Mountain View, CA), in those fetuses in which microsphere-determined cerebral blood flow determinations were planned during oxygenation and pulmonary ventilation (see "Experimental Procedure"). Then, after careful exposure of the main pulmonary artery, the ascending aorta, the aortic isthmus, and the brachiocephalic trunk, silicone rubber inflatable balloons were placed around the aortic isthmus and the brachiocephalic trunk. The fetal chest was sutured in layers. Next, the fetal head and neck were exposed through the same uterine incision. A $3.5-\mathrm{mm}$ endotracheal tube was connected by an $\mathrm{Y}$-tube to two $100-\mathrm{cm}$ lengths of flexible polyvinyl tubing (3.2-mm ID, 6.4-mm OD). The tubing was filled with $0.9 \%$ saline, and the trachea was intubated. A second catheter was placed into the amniotic cavity and connected to the ventilation tubing to allow tracheal fluid to flow freely from the uterus to the amniotic cavity postoperatively. After the carotid arteries in the neck were exposed, appropriately sized transonic flow transducers (Transonic Systems, Inc., Ithaca, NY) were applied to fit around the vessels to measure carotid blood flow
( $\mathrm{mL} / \mathrm{min}$ ). In the midline of the scalp, an incision was made to expose the cranial suture. The sagittal sinus was cannulated with a 20-gauge i.v. catheter (Becton Dickinson, Mountain View, CA) for collection of cerebral venous blood. Finally, the forelimb was exposed and a second polyvinyl catheter $(0.75-\mathrm{mm}$ ID, $1.2-\mathrm{mm}$ OD) was placed in the brachiocephalic trunk from the brachial artery. All incisions were sutured, the vascular catheters were filled with heparin sodium solution $(1000 \mathrm{U} / \mathrm{mL})$ and sealed, and all catheters and ventilation tubing were exteriorized to the maternal flank and protected by a cloth pouch. Antibiotics ( $400 \mathrm{mg}$ of gentamicin, 1 million $\mathrm{U}$ of penicillin) were given into the amniotic cavity and maternal vein on the day of surgery and each day thereafter. The animals were allowed $24-48 \mathrm{~h}$ to recover from surgery.

Physiologic measurements. Fetal blood pressures were monitored continuously using Statham P23Db strain-gauge transducers and a Beckman R612 (Beckman Instruments, Inc., Palo Alto, CA) or Gould 2800S (Gould, Inc., Cleveland, OH) polygraph. Fetal carotid and sagittal sinus blood pressures were calculated with amniotic cavity pressure as zero reference. Fetal heart rate, measured by a cardiotachometer and triggered by an arterial pulse wave, was recorded continuously. Blood samples for determination of $\mathrm{pH}, \mathrm{Po}_{2}, \mathrm{PCO}_{2}$, arterial and sagittal sinus oxygen saturation, and $\mathrm{Hb}$ concentration were obtained from the carotid artery and sagittal sinus.

Because we planned to measure brain blood flow frequently in each fetus (up to 16 determinations), to limit the number of animals used for this study, we used changes in fetal $Q_{c a r}$ to examine the relationship between brain flow and perfusion pressure. $\mathrm{Q}_{\text {car }}$ was measured using the transit time technique with Ultrasonics flow transducers. This method does not require a close contact of the flow transducer with the vessel $(15,16)$.

To evaluate $Q_{c a r}$ in estimating changes in (total) brain blood flow, we measured total fetal $\mathrm{Q}_{\text {brain }}$ and regional blood flow in hemispheres, cerebellum, and brainstem using radionuclidelabeled microspheres $\left({ }^{114} \mathrm{In},{ }^{153} \mathrm{Gd},{ }^{57} \mathrm{Co},{ }^{51} \mathrm{Cr},{ }^{113} \mathrm{Sn},{ }^{85} \mathrm{Sr}\right.$, ${ }^{95} \mathrm{Nb}$, and ${ }^{46} \mathrm{Sc}$ ) during a limited number of estimations of brain perfusion (up to eight per animal) while simultaneously monitoring $\mathrm{Q}_{\mathrm{car}}$ in both the nonventilation and the ventilation/ oxygenation conditions. $\mathrm{Q}_{\text {brain }}$ and regional blood flows to hemispheres, cerebellum, and brainstem were measured as described previously (17-19). We have previously reported on the relationship between $\mathrm{Q}_{\mathrm{car}}$ and $\mathrm{Q}_{\mathrm{brain}}$ measured with microspheres (19). We found a close linear relationship between $Q_{c a r}$ and $\mathrm{Q}_{\text {brain }}$ in these fetuses, but have not previously compared this relationship after indomethacin administration. The relationship was not altered by intrauterine pulmonary ventilation and oxygenation or indomethacin. Also, effects of indomethacin on regional blood flow were examined.

To ventilate the fetus, the tubes connected to the endotracheal tube were opened, and tracheal fluid was allowed to drain. Exosurf (Burroughs Wellcome) was instilled into the trachea, and the tubes were connected to a specially designed positive pressure ventilator (14).

$\mathrm{CO}_{2}$ and $\mathrm{CMRO}_{2}$ were determined as follows. $\mathrm{CO}_{2}$ was calculated as: grams $\mathrm{Hb} / \mathrm{dL} \times 1.36 \mathrm{~mL} \mathrm{O}_{2} / \mathrm{g} \mathrm{Hb} \times \%$ saturation of $\mathrm{Hb}$ with $\mathrm{O}_{2}$. $\mathrm{CMRO}_{2}$ was calculated as: (arterial $\mathrm{Co}_{2}-$ 
sagittal sinus $\left.\mathrm{CO}_{2}\right) \times$ brain blood flow; the result is expressed in $\mathrm{mL} \mathrm{O} / 100 \mathrm{~g}$ brain $/ \mathrm{min}$.

Experimental procedure. Nine fetuses were pretreated with indomethacin sodium trihydrate $(1 \mathrm{mg} / \mathrm{kg})$, in a randomized order; eight served as controls. Indomethacin was administered i.v. over a 10-min period. Indomethacin produced a modest transient increase in arterial blood pressure, which returned to pretreatment values within $10 \mathrm{~min}$. After reaching steady state (heart rate, arterial blood pressure, and $Q_{\text {car }}$ ), the fetuses were studied: 1) first without ventilation and then 2) during pulmonary ventilation with room air or with added oxygen to obtain blood gases normally seen in preterm newborns $\left(\mathrm{PO}_{2}, 45-100\right.$ $\mathrm{mm} \mathrm{Hg}$ ). We had previously shown that changes in brain blood flow and cerebral oxygen metabolism, initiated by ventilation and oxygenation of the lamb fetus, are similar to those that occur at birth (14).

During each condition, MCBP was decreased in steps of $5-10 \mathrm{~mm} \mathrm{Hg}$ by stepwise inflation of the brachiocephalic balloon, starting from baseline level. During baseline level and after each change in MCBP, when a steady state had been reached, blood samples were taken, hemodynamic parameters and $\mathrm{Q}_{\text {car }}$ registered, and $\mathrm{Q}_{\text {brain }}$ measured using microspheres. We aimed to decrease the MCBP well below the lower limit of cerebral autoregulation (see below). The brachiocephalic balloon was then released, and after reaching steady state again, MCBP was increased by steps of $10 \mathrm{~mm} \mathrm{Hg}$ by stepwise inflation of the aortic balloon to values of about $70 \mathrm{~mm} \mathrm{Hg}$, near the upper limit of cerebral autoregulation $(20,21) . \mathrm{Q}_{\text {brain }}$ and $\mathrm{CMRO}_{2}$ were determined at up to eight different cerebral perfusion pressures per animal during the fetal and/or neonatal condition.

Statistical analysis. Left and right carotid arterial blood flows were compared using single linear regression analysis. To test the relation between radioactive microspheredetermined $\mathrm{Q}_{\text {brain }}$ and simultaneously determined $\mathrm{Q}_{\text {car }}$, and the effect of ventilation with oxygen and indomethacin on this relation, we used a multiple linear regression model with the following equation:

$$
\begin{aligned}
& \mathrm{Y}=\mathrm{b}_{0}+\mathrm{b}_{\mathrm{Q}_{\text {brain }}} \mathrm{Q}_{\text {brain }}+\mathrm{b}_{\mathrm{V} \cdot \mathrm{V}} \mathrm{V}+\mathrm{b}_{\mathrm{I}} \mathrm{I}+\mathrm{b}_{\mathrm{Q}_{\text {brain }}} *{ }_{\mathrm{V}} \mathrm{Q}_{\text {brain }} * \mathrm{~V} \\
& +\mathrm{b}_{\mathrm{Q}_{\text {brain }}} *{ }_{\mathrm{l}} \mathrm{Q}_{\text {brain }} * \mathrm{I}+\sum_{k=1}^{19} \mathrm{~b}_{\mathrm{l}_{\mathrm{k}}} \mathrm{L}_{\mathrm{k}}
\end{aligned}
$$

where $\mathrm{Y}$ is the dependent variable $\mathrm{Q}_{\mathrm{car}}$ and $\mathrm{b}_{0}$ its overall mean value. $\mathrm{Q}_{\text {brain }}$ is the first independent variable and its coefficient $\mathrm{b}_{\mathrm{Q}_{\text {brain }}}$ defines the slope of the $\mathrm{Q}_{\text {car }}-\mathrm{Q}_{\text {brain }}$ relationship. These condV(noventilation/oxygenation: - 1; ventilation/oxygenation: +1$)$ and third $I($ no indomethacin: -1 ; pretreated with indomethacin: +1 ) are independent variables, whose coefficients $b_{V}$ and $b_{I}$ indicate the independent effect of ventilation/ oxygenation and indomethacin on $\mathrm{Q}_{\text {car }}$, respectively (affecting the intercept of the $\mathrm{Q}_{\mathrm{car}}-\mathrm{Q}_{\text {brain }}$ relationship). The fourth $\left(\mathrm{Q}_{\text {brain }} \cdot \mathrm{V}\right)$ and fifth $\left(\mathrm{Q}_{\text {brain }} \cdot \mathrm{I}\right)$ are action variables, whose coefficients $\mathrm{b}_{\mathrm{Q}_{\text {brain }}} * \mathrm{~V}$ and $\mathrm{b}_{\mathrm{Q}_{\text {brain }}} * \mathrm{I}$ indicate the interactive effect of ventilation/oxygenation and $\mathrm{Q}_{\text {brain }}$, and indomethacin and $\mathrm{Q}_{\text {brain }}$ on $\mathrm{Q}_{\mathrm{car}}$ (indicating the effect of ventilation/oxygenation and indomethacin on the slope of the $Q_{c a r}-Q_{\text {brain }}$ relationship).
Finally, to correct for inter animal variability, 19 dummy variables $\left(\mathrm{L}_{1}-\mathrm{L}_{19}\right)$ introduced for the 20 brain halves of 15 animals (see"Results") were included in this analysis (22). To determine the statistical significance of any variable, an $F$ test was performed by dividing the mean square of that variable by the mean square residual.

To define the lower limit breakpoint of cerebral autoregulation, the following approach was used. If cerebral autoregulation is present the relationship between cerebral perfusion pressure and cerebral blood flow would be nonlinear over the full range of perfusion pressures, but fairly linear below the lower limit, between the lower and upper limits and above the upper limit of the autoregulatory range. As we were interested in the lower limit range of the autoregulation, we defined two ranges of MCBP in which we investigated the relation between $\mathrm{Q}_{\text {car }}$ and MCBP separately, using a linear regression model: 1) between lowest MCBP values and the lower limit of cerebral autoregulation and 2) between MCBP values from the lower limit up to $70 \mathrm{~mm} \mathrm{Hg}$. In the control condition, the lower limit breakpoint of the autoregulatory plateau was determined mathematically by repetitively fitting a linear regression model through the data $\left(\mathrm{Q}_{\mathrm{car}}-\mathrm{MCBP}\right.$ relationship) above and below a test point using different test points in the range from 35 to 50 $\mathrm{mm} \mathrm{Hg}$, the range in which the lower limit of cerebral autoregulation should be as previously described $(20,21)$. To correct for interanimal variability, we included dummy variables to code the different animals (22). The breakpoint was defined as the test point where the sum of the residuals from the two fits was minimal $(21,23)$.

Finally, to investigate whether indomethacinhada significant effect on brain perfusion and on the autoregulatory ability of the cerebral vascular bed of the fetal lamb in the fetal and neonatal conditions, we analyzed the $\mathrm{Q}_{\mathrm{car}}-\mathrm{MCBP}$ relationship with and without indomethacin over the two defined pressure ranges in the nonventilated or ventilated/oxygenated fetuses separately. In both these conditions, we used the same multiple linear regression model with dummy variables in the above defined ranges with the following regression equation:

$$
\mathrm{Y}=\mathrm{b}_{0}+\mathrm{b}_{\mathrm{MCBP}} \mathrm{MCBP}+\mathrm{b}_{\mathrm{I}} \mathrm{I}+\mathrm{b}_{\mathrm{MCBP}{ }_{\mathrm{I}}} \mathrm{MCBP} * \mathrm{I}+\sum_{k=1}^{16} \mathrm{~b}_{\mathrm{l}_{\mathrm{k}}} \mathrm{L}_{\mathrm{k}}
$$

where $\mathrm{Y}$ is the dependent variable $\left(Q_{\mathrm{car}}\right)$ and $b_{0}$ is its overall mean value over all conditions and all animals. MCBP is the first independent variable, and its coefficient $b_{M C B P}$ defines the slope of the pressure-flow relationship, which is used as indicator of autoregulatory ability. If this parameter is not significant, there is autoregulation because flow does not depend on perfusion pressure. There is one (dummy) drug variable I (indomethacin), representing the control condition (value $=$ -1 ) or the indomethacin condition (value $=1$ ). The coefficient $b_{I}$ indicates the independent effect of indomethacin on $Q_{c a r}$, thus affecting the intercept of the $\mathrm{Q}_{\text {car }}-\mathrm{MCBP}$ relationship. The third independent variable is an interaction variable, MCBP.I, representing the interactive effect of indomethacin and MCBP on the $Q_{\text {car }}$. The coefficient $b_{M C B P .1}$ indicates therefore the effect of indomethacin on the slope of the $\mathrm{Q}_{\mathrm{car}}-\mathrm{MCBP}$ rela- 
tionship. To correct for interanimal variability, 16 dummy variables $\left(\mathrm{L}_{1}-\mathrm{L}_{16}\right)$ were introduced for the 17 animals included in this analysis (22). To determine the statistical significance of any variable, an $F$ test was performed by dividing the mean square of that variable by the mean square residual.

Differences among three or more values were investigated by analysis of variance for repeated measurements followed by the Newman-Keuls test if statistically significant differences were obtained. Statistical significance was assumed for $p<$ 0.05 .

\section{RESULTS}

Blood gases, arterial pressure, and blood flows (Table 1). During the control period, there were no differences between the nonventilated and ventilated fetuses, either before or after indomethacin administration, in blood $\mathrm{PCO}_{2}, \mathrm{pH}$, and $\mathrm{Hb}$ concentration, or in mean carotid blood pressure or cerebral oxygen consumption. Indomethacin resulted in a significant reduction in carotid arterial blood flow, in both nonventilated and ventilated fetuses, but the reduction was greater in the ventilated fetuses. Brain blood flow was also decreased by indomethacin in the nonventilated fetuses, but in the ventilated fetuses, the decrease was just not statistically significant $(p<0.07)$.

Relationship between left and right carotid arterial blood flow. Blood flow was measured in a single carotid artery, in seven fetuses and in both carotid arteries in 10 other fetuses. Blood flow in the left and right carotid arteries was not different [left, $33 \pm 19 \mathrm{~mL} / \mathrm{min}$; right, $33 \pm 19 \mathrm{~mL} / \mathrm{min}$ (mean $\pm \mathrm{SD})]$. Moreover, a close relationship was found between left and right with a slope of the regression line close to 1 ( $r=$ $0.85, p<0.0001, \mathrm{y}=0.95+3.762)$. We therefore assumed that total $Q_{\text {car }}$ was twice that measured in a single carotid artery in the seven fetuses.

Relationship between $Q_{\text {car }}$ and $\boldsymbol{Q}_{\text {brain }}$. In 15 of the 17 animals, radionuclide-labeled microsphere determinations of the brain blood flow were compared with simultaneously determined $\mathrm{Q}_{\mathrm{car}}$ in eight fetuses before ventilation/oxygenation (four control, four indomethacin-pretreated fetuses). Because blood flow was not measured in both carotid arteries in all fetuses, we compared $\mathrm{Q}_{\mathrm{brain}}$ in the hemisphere on the same side on which $Q_{\text {car }}$ was measured (19). The multiple linear regression analysis revealed a close relationship between $\mathrm{Q}_{\text {car }}$ and $\mathrm{Q}_{\text {brain }}(r=0.95, p<0.0001)$. Neither indomethacin nor ventilation/oxygenation had an effect on the intercept or the slope of the regression line of the relationship. There was no significant interanimal variability.

Changes in $\mathrm{Q}_{\text {car }}$ and $\mathrm{Q}_{\text {brain }}$ and in perfusion pressure are shown in Figure 1 (all $Q_{c a r}$ data are included). $Q_{c a r}$ and $Q_{\text {brain }}$ averaged for MCBP ranges of $5 \mathrm{~mm} \mathrm{Hg}$ showed a similar pattern of change in nonventilated and ventilated fetuses, with or without indomethacin. It is also noted that ventilation and oxygenation decreased $\mathrm{Q}_{\mathrm{car}}$ and $\mathrm{Q}_{\text {brain }}$ over the whole pressure range.

Lower limit of cerebral autoregulation. The calculated lower limit of autoregulatory ability of the vascular bed in the control animals was $43 \mathrm{~mm} \mathrm{Hg}$. Ventilation with oxygenation had no influence on this limit. These values are in accordance with data in the literature $(20,21)$. We therefore suggest that cerebral autoregulation was operative over the range of 44-70 $\mathrm{mm} \mathrm{Hg}(20,21)$ and that autoregulation was not operative at MCBP below $44 \mathrm{~mm} \mathrm{Hg}$.

Influence of indomethacin on cerebral blood flow $\left(Q_{\text {car }}\right)$ and cerebral metabolism $\left(\mathrm{CMRo}_{2}\right)$ in nonventilated fetuses. Using the multiple linear regression model, we found a direct relation between $\mathrm{MCBP}$ and $\mathrm{Q}_{\mathrm{car}}\left(\mathrm{b}_{\mathrm{MCBP}}, 2.55 \mathrm{~mL} \cdot \mathrm{min}^{-1} / \mathrm{mm}\right.$ $\mathrm{Hg} ; p<0.0001)$ at MCBP values below $44 \mathrm{~mm} \mathrm{Hg}$. Indomethacin, however, had no effect on this pressure-flow relationship. In contrast, at MCBP values between 44 and $70 \mathrm{~mm}$ $\mathrm{Hg}$, indomethacin did affect the intercept of the pressure-flow relationship significantly $(p<0.0001)$. This indicates that indomethacin had a pressure-independent effect on flow, resulting in a considerable decrease in flow at all pressure levels $\left(b_{I},-57.5 \mathrm{~mL} \cdot \mathrm{min}^{-1}\right)$. However, indomethacin had no cffect on the slope of the pressure-flow relationship ( $\left.b_{M C B P \cdot I}, N S\right)$. There was no significant interanimal variability in the investigated MCBP ranges. The mean values of $\mathrm{CMRO}_{2}$ in the control as well as in the indomethacin-pretreated fetuses were significantly lower at MCBP below $30 \mathrm{~mm} \mathrm{Hg}$ compared with those at pressures of $44-70 \mathrm{~mm} \mathrm{Hg}$. However, there was no significant difference between control and indomethacin-pretreated animals (Table 2).

Table 1. Arterial blood gases, $p H$, hemoglobin, $M C B P, Q_{c a}$, microsphere-determined $Q_{\text {brain, }} C M R o_{2}$ at baseline levels in nonventilated and ventilated/oxygenated control and indomethacin-pretreated fetuses (means $\pm 1 S D$ )

\begin{tabular}{|c|c|c|c|c|}
\hline & \multicolumn{2}{|c|}{ Nonventilated Fetuses } & \multicolumn{2}{|c|}{ Ventilated and Oxygenated Fetuses } \\
\hline & $\begin{array}{l}\text { Control } \\
(n=8)\end{array}$ & $\begin{array}{l}\text { Indomethacin } \\
\qquad(n=9)\end{array}$ & $\begin{array}{l}\text { Control } \\
(n=7)\end{array}$ & $\begin{array}{l}\text { Indomethacin } \\
\quad(n=8)\end{array}$ \\
\hline $\mathrm{pH}$ & $7.35 \pm 0.07$ & $7.36 \pm 0.04$ & $7.41 \pm 0.05$ & $7.36 \pm 0.12$ \\
\hline $\mathrm{PCO}_{2}(\mathrm{~mm} \mathrm{Hg})$ & $53 \pm 5$ & $53 \pm 6$ & $47 \pm 4$ & $48 \pm 6$ \\
\hline $\mathrm{PO}_{2}(\mathrm{~mm} \mathrm{Hg})$ & $20 \pm 4$ & $22 \pm 3$ & $58 \pm 26^{*}$ & $63 \pm 15 \dagger$ \\
\hline Hemoglobin concentration $(\mathrm{g} / \mathrm{dL})$ & $12.3 \pm 1.5$ & $11.0 \pm 1.8$ & $10.9 \pm 1.6$ & $11.7 \pm 1.5$ \\
\hline MCBP $(\mathrm{mm} \mathrm{Hg})$ & $58 \pm 8$ & $57 \pm 7$ & $53 \pm 6$ & $58 \pm 6$ \\
\hline $\mathrm{Q}_{\text {car }}(\mathrm{mL} / \mathrm{min})$ & $102 \pm 54$ & $78 \pm 30^{*}$ & $65 \pm 21 \dagger$ & $37 \pm 9^{*}, \dagger$ \\
\hline $\mathrm{Q}_{\text {brain }}(\mathrm{mL} / 100 \mathrm{~g} / \mathrm{min})$ & $125 \pm 73 \quad(n=6)$ & $66 \pm 15^{*}(n=6)$ & $63 \pm 24 \S(n=5)$ & $42 \pm 14 \dagger(n=6)$ \\
\hline $\mathrm{CMRO}_{2}\left(\mathrm{~mL} \mathrm{O}_{2} / 100 \mathrm{~g} / \mathrm{min}\right)$ & $3.9 \pm 1.2(n=5)$ & $4.1 \pm 1.2(n=5)$ & $3.8 \pm 1.5(n=5)$ & $4.6 \pm 1.7(n=5)$ \\
\hline
\end{tabular}

${ }^{*} p<0.05$ vs control.

$\dagger p<0.05$ vs fetal control/indomethacin.

$\S p<0.05$ vs fetal control. 


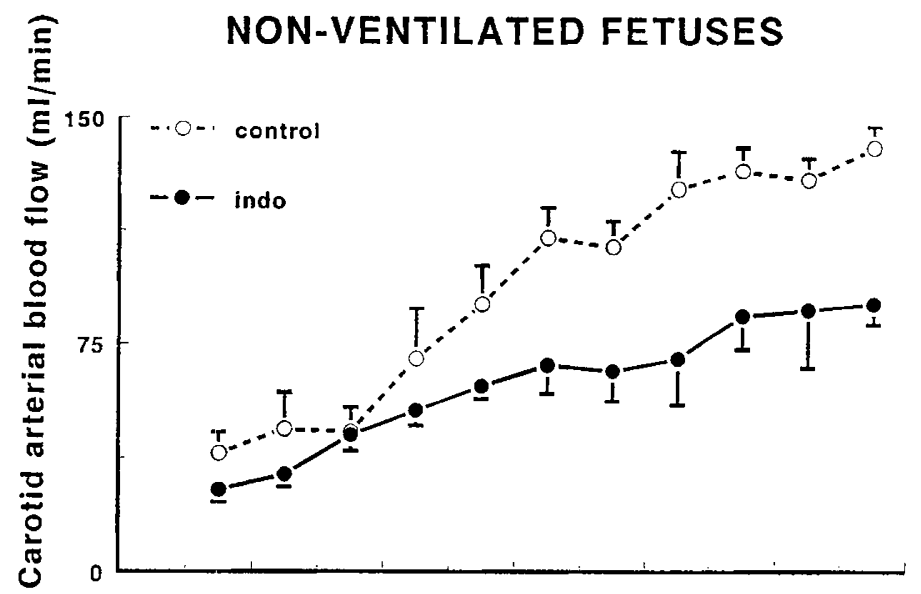

VENTILATED/OXYGENATED FETUSES
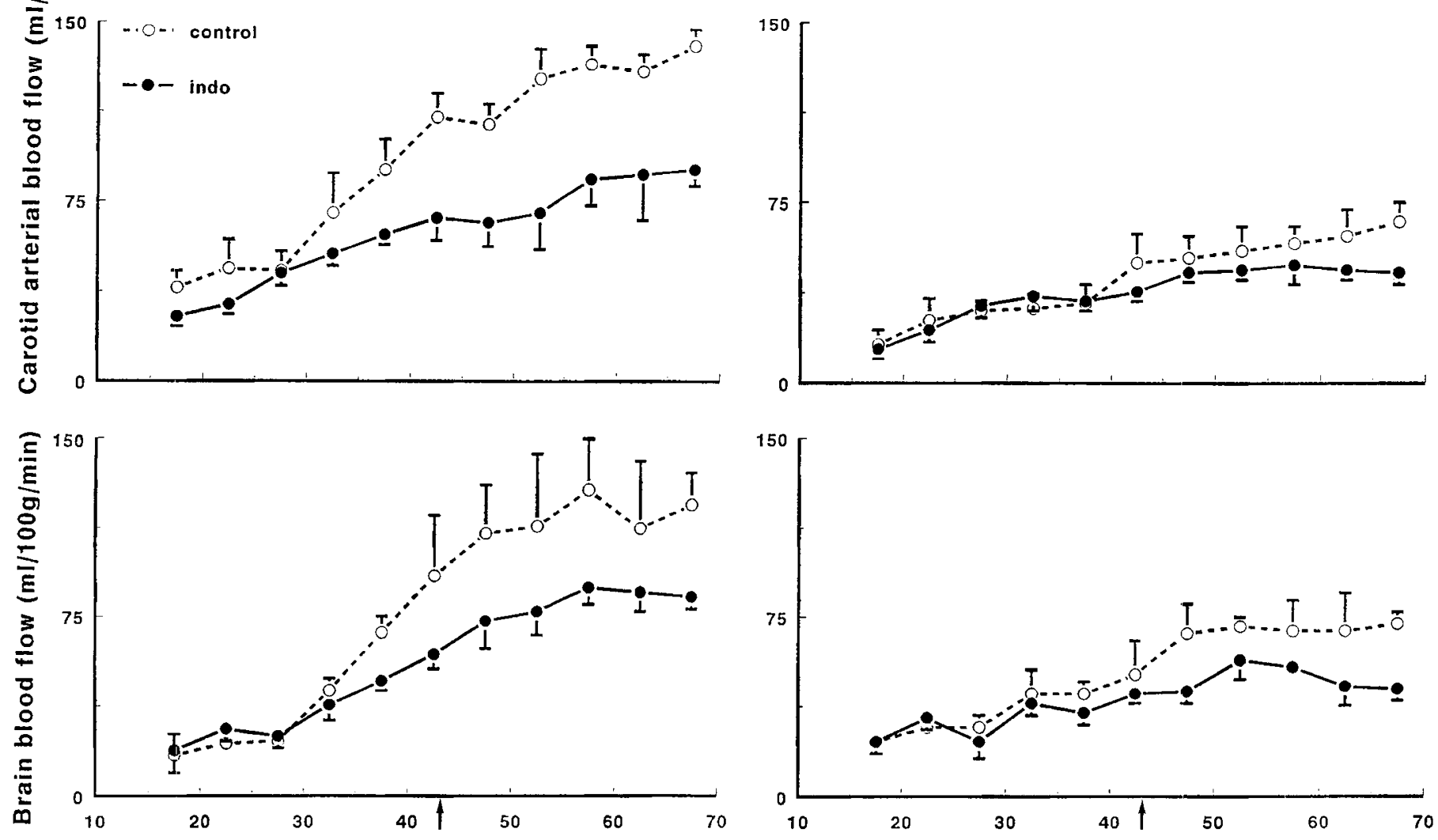

$\operatorname{MCBP}(\mathrm{mmHg})$

Figure 1. $Q_{\mathrm{car}}$ and radionuclide-labeled microsphere-determined $\mathrm{Q}_{\mathrm{brain}}$ (means $\pm \mathrm{SEM}$ ) of control and indomethacin-pretreated fetuses during nonventilation and ventilation/oxygenation conditions as a function of MCBP. $Q_{c a r}$ and $Q_{b r a i n}$ were averaged for MCBP ranges of $5 \mathrm{~mm} \mathrm{Hg}$. Data for the $Q_{c a r}$ values were derived from all 17 lamb fetuses, whereas data for $\mathrm{Q}_{\text {brain }}$ values were derived from the 15 fetuses in which microspheres were used. The arrows indicate the MCBP value at which the lower limit of cerebral autoregulation was calculated (43 $\mathrm{mm} \mathrm{Hg}$ in both instances).

Table 2. Values (means \pm I SD) of $\mathrm{CMRO}_{2}(\mathrm{~mL} / 100 \mathrm{~g} / \mathrm{min}$ ) subdivided in MCBP ranges from 0 to $29 \mathrm{~mm} \mathrm{Hg}$, from 30 to $43 \mathrm{~mm} \mathrm{Hg}$, and from 44 to $70 \mathrm{~mm} \mathrm{Hg}$ (calculated lower limit of cerebral autoregulation $43 \mathrm{~mm} \mathrm{Hg}$ in both instances) of the nonventilated control and indomethacin-pretreated lamb fetuses, and the ventilated/oxygenated control and indomethacin-pretreated lamb fetuses

\begin{tabular}{cccccc}
\hline & \multicolumn{2}{c}{ Nonventilated Fetuses $(n=8)$} & & \multicolumn{2}{c}{ Ventilated and Oxygenated Fetuses $(n=8)$} \\
\cline { 2 - 3 } MCBP-range (mm Hg) & Control & $1.64 \pm 0.69$ & & Control & Indomethacin \\
\hline 0 to 29 & $3.34 \pm 1.29^{*}$ & $1.96 \pm 1.50$ & & $1.78 \pm 0.59$ & $2.18 \pm 1.25$ \\
30 to 43 & $3.89 \pm 1.18 \dagger$ & $3.84 \pm 1.07^{*}$ & & $3.58 \pm 0.53$ & $3.58 \pm 1.38^{*}$ \\
44 to 70 & & & & & \\
\hline
\end{tabular}

${ }^{*} p<0.05$.

$\dagger p<0.001$ (vs $0-29 \mathrm{~mm} \mathrm{Hg}$ range).

Influence of indomethacin on cerebral blood flow $\left(Q_{\text {car }}\right)$ and $\mathrm{CMRO}_{2}$ in ventilated and oxygenated fetuses. As in the nonventilated fetuses, the multiple linear regression model showed a direct relation between MCBP and $\mathrm{Q}_{\mathrm{car}}\left(\mathrm{b}_{\mathrm{MCBP}}, 0.89\right.$ $\mathrm{mL} \cdot \mathrm{min}^{-1} / \mathrm{mm} \mathrm{Hg} ; p<0.0001$ ) below $44 \mathrm{~mm} \mathrm{Hg}$. Again, indomethacin had no effect on the pressure-flow relationship. Between MCBP values of 44 and $70 \mathrm{~mm} \mathrm{Hg}$, however, indomethacin significantly reduced the slope of the pressure-flow relationship from 0.47 to $0.20 \mathrm{~mL} / \mathrm{min}^{-1} / \mathrm{mm} \mathrm{Hg}\left(b_{\text {MCBP.I }}\right.$, $0.27 \mathrm{~mL} \cdot \mathrm{min}^{-1} / \mathrm{mm} \mathrm{Hg} ; p<0.05$ ). This suggests that indomethacin improves the autoregulatory ability of the cerebral vascular bed. Indomethacin did not affect the intercept of the pressure-flow relationship $\left(b_{I}, N S\right)$ in the MCBP ranges stud- ied. There was no significant interanimal variability. The mean values of $\mathrm{CMRO}_{2}$ in both control and indomethacin-pretreated fetuses were significantly lower at MCBP below $30 \mathrm{~mm} \mathrm{Hg}$ compared with those at pressures of $44-70 \mathrm{~mm} \mathrm{Hg}$. Moreover, there was no significant difference between control and indomethacin-pretreated animals at any MCBP range (Table 2). Moreover, $\mathrm{CMRO}_{2}$ determinations in these ranges in both controls and indomethacin-treated lambs did not differ between nonventilated and ventilated fetuses.

Pattern of regional brain blood flow. Although blood flow to the cerebellum and brainstem tended to be higher than hemispheric and midbrain blood flow, the difference was never significant, irrespective of ventilation, indomethacin pretreat- 
ment, or MCBP value. In the nonventilated as well as in ventilated/oxygenated fetuses, total brain $\left(\mathrm{Q}_{\text {brain }}\right)$, hemispheric/midbrain, and cerebellar/brainstem blood flows were all significantly lower below MCBP values of $44 \mathrm{~mm} \mathrm{Hg}$ compared with values between MCBP of 44 and $70 \mathrm{~mm} \mathrm{Hg}$. Figure 2 summarizes these results. This figure also illustrates that proportions of blood flow to the different brain regions did not change under the influence of indomethacin pretreatment.

\section{DISCUSSION}

Several studies have reported a decrease in the incidence of severe periventricular-intraventricular hemorrhage in premature babies treated prophylactically with indomethacin (1-5). It has been suggested that this effect may be the result of reduction of cerebral hyperemia by indomethacin. Also, the possibility has also been raised that indomethacin enhances autoregulatory ability of the neonatal cerebral circulation, thus limiting hyperemia associated with asphyxia and hypercapnia $(10,11)$. However, the decrease in cerebral blood flow resulting from indomethacin has raised concern regarding its use in attempting to prevent the development of intraventricular hemorrhage in preterm infants. The possibility that the reduced cerebral blood flow resulting from indomethacin administration may interfere with cerebral oxygenation, and thus cause cerebral damage, has raised questions about the use of the drug as a prophylactic agent. Thus, Baerts et al. (13), in a retrospective study, found a higher incidence of periventricular leu- komalacia in the infants of mothers in whom indomethacin was administered to inhibit preterm labor. Also, Leffler et al. (24) reported that indomethacin accentuated the decrease of cerebral blood flow and cerebral oxygen consumption during hypotension in piglets.

In this study, we measured carotid blood flow continuously to reflect changes in cerebral blood flow. We had previously demonstrated that there is a very close relationship between carotid and cerebral blood flows in fetal lambs over a wide range of arterial pressures (19). It was necessary to demonstrate, however, that cerebral vasoconstriction induced by indomethacin, or associated with ventilation and oxygenation, did not influence this relationship. We showed that the relationship between carotid blood flow, as measured by ultrasonic flow transducers and cerebral blood flow, measured by the radionuclide-labeled microspheres, was maintained during all the experimental manipulations. This further confirms the validity of the use of carotid blood flow changes as an estimate of cerebral blood flow changes in the fetal lamb, both in the control status and after indomethacin administration. Our interest in this observation is due to the fact that a large number of observations of cerebral blood flow can be made in a single animal, whereas only a limited number of measurements can be made using microspheres. The use of carotid blood flow as an index of cerebral blood flow changes could help to reduce the number of animals used for these studies. Whether carotid blood flow changes can be used to reflect cerebral blood flow

\section{NON-VENTILATED FETUSES}
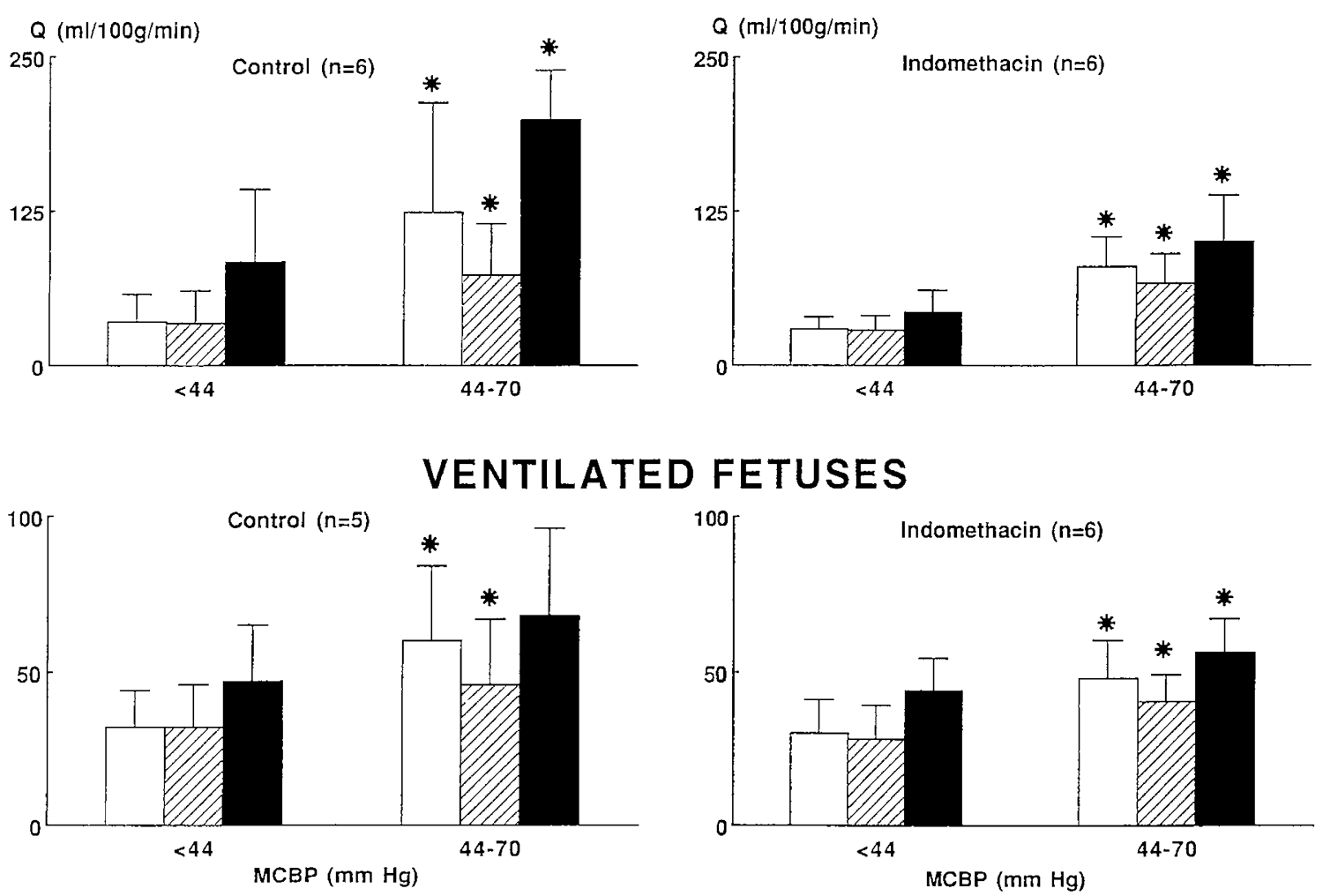

Figure 2. Values (means \pm SD) of total brain blood flow $(\square)$, hemispheric/midbrain (络), and cerebellar/brainstem ( $\mathbf{\square}$ ) blood flow below and above the calculated lower limit of cerebral autoregulation (43 mm Hg in both instances) of the nonventilated control and indomethacin-pretreated lamb fetuses, and the ventilated/oxygenated control and indomethacin-pretreated lamb fetuses. ${ }^{*} p<0.05$ vs $\mathrm{MCBP}<44 \mathrm{~mm} \mathrm{Hg}$. 
changes in human infants is yet to be demonstrated. Cerebral blood flow as a percentage of cardiac output is much higher in the human compared with the sheep, and thus could be more reliably represented by large arterial flow. However, in the human, a larger proportion of cerebral flow is derived from the vertebral arteries, whereas in the sheep, flow is provided largely by the carotid arteries.

Analysis of our data demonstrated that the breakpoint of the mean perfusion pressure below which autoregulation was not evident was $44 \mathrm{~mm} \mathrm{Hg}$, in both the ventilated and nonventilated control fetuses. Although this is not readily apparent in Figure 1, this was confirmed by nonlinear regression analysis in both nonventilated and ventilated fetuses that were pretreated with indomethacin. However, at pressures between 44 and $70 \mathrm{~mm} \mathrm{Hg}$, indomethacin reduced carotid blood flow in both ventilated and nonventilated fetuses. Carotid and cerebral blood flows were higher in the nonventilated fetuses and fell to a greater extent after indomethacin than did that of the oxygenated fetuses. This is probably related to the fact that oxygenation had already produced considerable cerebral vasoconstriction, so that indomethacin caused only limited additional vasoconstriction. At lower perfusion pressures, indomethacin had little effect on reducing flow further in either the ventilated or nonventilated fetuses. This is of considerable interest; below the autoregulatory range of pressure, the cerebral vessels are well dilated. It is evident that the mechanisms responsible for vasodilation are not related to prostaglandins and are sufficiently powerful to overcome the constrictor effect of indomethacin. This hypothesis is supported by the observation of Norins et al. (25) that feline cerebral arteries constricted when exposed to indomethacin, but again dilated if $\mathrm{Po}_{2}$ was lowered to hypoxic levels. In the ventilated and oxygenated fetuses, indomethacin flattened the slope of the $Q_{c a r}$ to a mean carotid arterial pressure relationship; this suggests that it also improves cerebral autoregulation in the newborn animal. We cannot explain why indomethacin altered the slope of the pressureflow relationship in the ventilated/oxygenated and not in the nonventilated fetuses. Possibly, this could be related to the fact that cerebral vasoconstriction results from oxygenation, and that the additional vasoconstriction induced by indomethacin allowed more effective autoregulation.

At cerebral perfusion pressures below $30 \mathrm{~mm} \mathrm{Hg}$, cerebral oxygen consumption fell significantly in the nonventilated fetuses. Of note, though, was the fact that indomethacin administration caused no further fall in oxygen consumption. In the ventilated and oxygenated fetuses, there was no significant fall in oxygen consumption at low perfusion pressures. This was related to the higher oxygen content of blood delivered to the brain. Of great importance was our finding that indomethacin had no effect on oxygen consumption of the brain at those lower perfusion pressures.

In earlier experimental studies it had already been shown that indomethacin did not alter brain blood flow distribution in newborn piglets $(24,26)$. We also found no significant differences in the proportion of cerebral blood flow to different regions of the brain of the fetal lamb, neither over low perfusion pressure ranges nor over perfusion ranges between 44 and $70 \mathrm{~mm} \mathrm{Hg}$.
It is important to stress that caution should be exercised in automatically extrapolating our findings in fetal sheep with gestational ages ranging from 123 to $135 \mathrm{~d}$ to preterm infants, whose brains are less mature relative to those of fetal lambs with the gestational ages studied (27). Finally, there may be disagreement about the dose of indomethacin used in the present study. The dose we used $(1 \mathrm{mg} / \mathrm{kg})$ is about $3-4$ times the dose usually administered to the preterm baby $(0.1-0.3$ $\mathrm{mg} / \mathrm{kg}$ ). However, the dose used was necessary to produce circulatory changes. In this respect it is important to realize that indomethacin, given to the fetus, is not only distributed in fetal tissues, but also passes into the maternal circulation and tissues, a huge distribution pool. In fact, most studies in newborn lambs have been performed with much higher dosages than used in our study. Also, some experimental and clinical studies have shown that the effects of indomethacin on the perfusion of the brain and other organs are relatively dose-independent $(12,28-31)$.

We have demonstrated that indomethacin reduces cerebral blood flow in the lamb fetus under normal fetal blood gas conditions, whereas it flattened the perfusion pressure-brain blood flow relationship in those fetuses ventilated and oxygenated to simulate the neonatal state, suggesting improvement of cerebral autoregulating function. Although it reduces cerebral blood flow, it does so without compromising cerebral metabolism, as measured by cerebral oxygen consumption, even at low cerebral perfusion pressures.

\section{REFERENCES}

1. Ment LR, Duncan CC, Ehrenkranz RA, Kleinman CS, Pitt BR, Taylor KJW, Scott DT, Stewart WB, Gettner P 1985 Randomized indomethacin trial for prevention of intraventricular hemorrhage in very low birth weight infants. J Pediatr 107:937-943

2. Hanigan WC, Kennedy G, Roemisch F, Anderson R, Cusack T, Powers W 1988 Administration of indomethacin for the prevention of periventricular-intraventricular hemorrhage in high-risk neonates. J Pediatr 112:941-947

3. Ment LR, Duncan CC, Ehrenkranz RA, Kleinman CS, Taylor KJ, Scott DT, Gettner P, Sherwonit E, Williams J 1988 Randomized low-dose indomethacin trial for prevention of intraventricular hemorrhage in very low birth weight neonates. J Pediatr 112:948-955

4. Bandstra ES, Montalvo BM, Goldberg RN, Pacheco I, Ferrer PL, Flynn J, Gregorios JB, Bancalari E 1988 Prophylactic indomethacin for prevention of intraventricular hemorrhage in premature infants. Pediatrics 82:533-542

5. Bada HS, Green RS, Pourcyrous M, Leffler CW, Korones SB, Magill HL, Arheart K, Fitch CW, Anderson GD, Somes G, Tullis K, Campbell J 1989 Indomethacin reduces the risks of severe intraventricular hemorrhage. J Pediatr 115:631-637

6. Hutchison AA, Ogletree ML, Palme CJ, Leheup BP, Barrett JM, Fleischer AC, Stahlman MT, Brigham KL 1985 Plasma 6-keto prostaglandin $F_{1 \alpha}$ and thromboxane $B_{2}$ in sick preterm neonates. Prostaglandins Leukot Med 18:163-181

7. Rennie JM, Doyle J, Cooke RW 1987 Elevated levels of immunoreactive prostacyclin metabolite in babies who develop intraventricular haemorrhage. Acta Paediatr Scand $76: 19-23$

8. Wennmalm A, Erikson S, Wahren J 1981 Effect of indomethacin on basal and carbon dioxide stimulated cerebral blood flow in man. Clin Physiol 1:227-234

9. De Giulio PA, Cameron CF, Mishra OP, Delivoria-Papapopoulos M, Wagerle LC 1990 Differential effect of ibuprofen and indomethacin on cortical prostanoids and pial arteriolar diameter during hypercapnia in newborn piglets. Pediatr Res 27:233A(abstr)

10. Chemtob S, Beharry K, Rex J, Varma DR, Aranda JV 1990 Changes in cerebrovascular prostaglandins and thromboxane as a function of systemic blood pressure. Cerebral blood flow autoregulation of the newborn. Circ Res 67:674-682

11. van Bel F, Klautz RJ, Steendijk P, Schipper IB, Teitel DF, Baan J 1993 The influence of indomethacin on the autoregulatory ability of the cerebral vascular bed in the newborn lamb. Pediatr Res 34:178-181

12. Leffler CW, Busija DW, Beasley DG 1987 Effect of therapeutic dose of indomethacin on the cerebral circulation of newborn pigs. Pediatr Res 21:188-192

13. Baerts W, Fetter WP, Hop WC, Wallenburg HC, Spritzer R, Sauer PJ 1990 Cerebral lesions in preterm infants after tocolytic indomethacin. Dev Med Child Neurol 32:910-918

14. Iwamoto HS, Teitel D, Rudolph AM 1987 Effects of birth-related events on blood flow distribution. Pediatr Res 22:634-640 
15. Dobson AD, Sellers AF, McLeod FD 1986 Performance of a cuff-type blood flowmeter in vivo. J Appl Physiol 21:1642-1648

16. Hartman J, Koernier J, Lancaster L, Gorczynski R 1985 In vivo calibration of transit-time ultrasound system for measuring ascending aorta volume flow. Pharmacologist 27:127-132

17. Heymann MA, Payne BD, Hoffman JIE, Rudolph AM 1977 Blood flow measurements with radionuclide-labeled particles. Prog Cardiovasc Dis 20:55-79

18. Baer RW, Payne BA, Verrier ED, Vlahakes GJ, Molodowitch D, Uhlig PN, Hoffman JIE 1984 Increased number of myocardial blood flow measurements with radionuclide-labeled microspheres. Am J Physiol 246:H418-H434

19. van Bel F, Roman C, Klautz RJM, Teitel DF, Rudolph AM 1994 Relationship between brain blood flow and carotid arterial flow in the sheep fetus. Pediatr Res 35:329-333

20. Purves MJ, Jamcs IM 1969 Observations on the control of cerebral blood flow in the sheep fetus and newborn lamb. Circ Res 25:651-667

21. Szymonowicz W, Walker AM, Yu VY, Stewart ML, Cannata J, Cussen L 1990 Regional cerebral blood flow after hemorrhagic hypotension in the preterm, nearterm, and newborn lamb. Pediatr Res 28:361-366

22. Slinker BK, Glantz SA 1990 Missing data in two-way analysis of variance. Am Physiol 258:R291-R297

23. Orr GW, Green HJ, Hughson RL, Bennett GW 1982 A computer linear regressio model to determine ventilatory anaerobic threshold. J Appl Physiol 52:1349-1352
24. Leffler CW, Busija DW, Beasley DG, Fletcher AM 1986 Maintenance of cerebral circulation during hemorrhagic hypotension in newborn pigs: Role of prostanoids. Circ Res 59:562-567

25. Norins NA, Wendelberger K, Hoffman RG, Keller PA, Madden JA 1992 Effects of indomethacin on myogenic contractile activation and responses to changes in $\mathrm{O}_{2}$ and $\mathrm{CO}_{2}$ in isolated feline cerebral arteries. J Cereb Blood Flow Metab 12:866-872

26. Coyle MG, Oh W, Stonestreet BS 1991 Effects of indomethacin on brain blood flow and cerebral metabolism in hypoxic newborn piglets. Am J Physiol 264:H141-H149

27. Raju TNK 1992 Some animal models for the study of perinatal asphyxia. Biol Neonate 62:193-201

28. Lefler CW, Busija DW, Fletcher AM, Beasley DG, Hessler JR, Green RS 1985 Effects of indomethacin upon cercbral hemodynamics of newborn pigs. Pediatr Res 19:1160-1164

29. Naden RP, lliya CA, Arant BS, Gant NF, Rosenfeld CR 1985 Hemodynamic effects of indomethacin in chronically instrumented pregnant sheep. Am J Gynccol 151:484493

30. Chemtob S, Beharry K, Barna T, Varma DR, Aranda JV 1991 Differences in the effects in the newborn piglet of various non steroidal antiinflammatory drugs on cerebral blood flow but not on cerebral prostaglandin. Pediatr Res 30:106-111

31. Cowan F 1986 Indomethacin, patent ductus arteriosus and cerebral blood flow. J Pediatr 109:341-344 